NBER WORKING PAPER SERIES

\title{
ADVERSE SELECTION IN HEALTH \\ INSURANCE
}

David M. Cutler

Richard J. Zeckhauser

Working Paper 6107

\author{
NATIONAL BUREAU OF ECONOMIC RESEARCH \\ 1050 Massachusetts Avenue \\ Cambridge, MA 02138 \\ July 1997
}

This paper was prepared for the National Bureau of Economic Research conference on Frontiers in Health Policy Research, June 5, 1997. We are grateful to Dan Altman and Srikanth Kadiyala for assistance, and to Sarah Reber, Charles Slavin, and Miriam Avins for helpful discussions. This work was supported by a grant from the National Institute on Aging to the NBER as well as from TIAA to Harvard. This paper is part of NBER's research programs in Health Care and Public Economics. Any opinions expressed are those of the authors and not those of the National Bureau of Economic Research.

(C) 1997 by David M. Cutler and Richard J. Zeckhauser. All rights reserved. Short sections of text, not to exceed two paragraphs, may be quoted without explicit permission provided that full credit, including (C) notice, is given to the source. 
Adverse Selection in Health Insurance

David M. Cutler and Richard J. Zeckhauser

NBER Working Paper No. 6107

July 1997

Health Care and Public Economics

\section{ABSTRACT}

Individual choice over health insurance policies may result in risk-based sorting across plans. Such adverse selection induces three types of losses: efficiency losses from individuals being allocated to the wrong plans; risk sharing losses since premium variability is increased; and losses from insurers distorting their policies to improve their mix of insureds. We discuss the potential for these losses, and present empirical evidence on adverse selection in two groups of employees: Harvard University, and the Group Insurance Commission of Massachusetts (serving state and local employees). In both groups, adverse selection is a significant concern. At Harvard, the University's decision to contribute an equal amount to all insurance plans led to the disappearance of the most generous policy within 3 years. At the GIC, adverse selection has been contained by subsidizing premiums on a proportional basis and managing the most generous policy very tightly. A combination of prospective or retrospective risk adjustment, coupled with reinsurance for high cost cases, seems promising as a way to provide appropriate incentives for enrollees and to reduce losses from adverse selection.

David M. Cutler

Department of Economics

Harvard University

Cambridge, MA 02138

and NBER

dcutler@nber.org
Richard J. Zeckhauser

Kennedy School of Government

Harvard University

79 John F. Kennedy Street

Cambridge, MA 02138

and NBER

richardz@ksg1.harvard.edu 
Individuals who expect high health care costs differentially prefer more generous and expensive insurance plans; those who expect low costs choose more moderate plans. This phenomenon, called adverse selection, is a major theoretical concern in health insurance markets. Adverse selection has the potential to lead to three classes of inefficiencies: prices to participants will not reflect marginal costs, hence on a benefit-cost basis individuals will select the wrong health plans; desirable risk spreading is lost; and health plans will manipulate their offerings to deter the sick and attract the healthy.

Discussions of health care reform have often become stuck over the issue of adverse selection. Concerns about adverse selection have been raised in the context of Medicare reform, changes in employment-based health insurance, and the efficiency of individual insurance markets (see Cutler, 1996, for discussion). But how important are these concerns empirically? Should we be greatly worried about adverse selection, or consider it a minor issue? What measures might mitigate its effects?

We address these issues in this paper, focusing in particular on individual choice of a health insurance plan from a menu set by their employer. We draw heavily on case studies of two entities for which we have detailed information the enables us to assess the importance of adverse selection: Harvard University and the Group Insurance Commission of Massachusetts. We conclude that adverse selection is a real and growing issue in a world where most employers offer multiple alternative insurance policies. Adverse selection eliminated the market for a generous Preferred Provider Organization at Harvard and threatens to do the same with a generous indemnity policy at the Group Insurance Commission, absent measures to diminish adverse selection. 
We begin the paper with a discussion of adverse selection. We then consider the empirical importance of this phenomenon, using data from our two examples. Finally, we discuss strategies -- including mandatory reinsurance and payment adjustments to plans that enroll high risks -- to mitigate the effects of adverse selection.

\section{The Theory of Adverse Selection}

We illustrate the issues involved in adverse selection by considering a situation of employer-administered health plans, although the situation could just as well apply to government-sponsored insurance or individuals purchasing insurance on their own. Typically, employers offer individuals multiple health plans to promote competition and to cater to individual tastes in styles of medical care delivery and choice of medical providers.

When employers set out multiple insurance offerings and allow insurers flexibility in the design of their plans, there is the possibility that high risk individuals will differentially choose some plans and low risks another. We label this process differential selection. When differential selection arises because individuals are not charged marginal cost when switching between plans, it is called adverse selection, and it has efficiency implications.

Three parties play a role in differential selection. Insurers set premiums on the basis of the riskiness of the people they enroll and their negotiations with employers. Employers pay some portion of the premiums, and require some contribution by employees. Employees choose a health care plan on the basis of a benefit/cost calculation - those who believe they are likely to need more care buy the more expensive policy — as well as preferences such as the plans' 
geographic locations, whether they can see their long-term doctors, or whether the plan is recommended by friends. If such preferences play a sufficiently strong role, risk-based selection will be a minor consideration; as they become less important, adverse selection increases.

Figure 1 shows how the confluence of actions by insurers, employers, and employees produces an outcome yielding plan premiums, employee charges, and an allocation of people to plans. This process can lead to inefficient allocation of employees across plans, incomplete risk spreading, and perverse incentives for plans to differentially attract particular employees, as we now show.

Adverse Selection and Inefficient Allocation: An Example. We illustrate the adverse selection process with a simple hypothetical example. An employer offers two health plans, a generous plan and a moderate plan. We also assume two types of individuals -- high risk and low risk. The costs for treating individuals under the plans, and their gains in benefit from the generous plan, are:

\begin{tabular}{|c|c|c|c|c|}
\hline & \multicolumn{3}{|c|}{ Resource Costs of Coverage } & \multirow{2}{*}{$\begin{array}{c}\text { Benefit Difference } \\
\text { Generous Less } \\
\text { Moderate Plan }\end{array}$} \\
\hline & Moderate & Generous & Difference & \\
\hline Low-risk Individuals & $\$ 40$ & $\$ 60$ & $\$ 20$ & $\$ 15$ \\
\hline High-risk Individuals & 70 & 100 & 30 & 40 \\
\hline
\end{tabular}

High risks are more expensive than low risks, and spending is greater under the generous plan for each risk type. The last column shows the posited gain in benefits the different types of individuals receive from the generous as opposed to the moderate plan. It is assumed that high- 
risks benefit more than low-risks from increased plan generosity.

The efficient outcome in this example is for high-risk people to be in the more generous plan and low risk people to be in the moderate plan. High risks should be in the generous plan because the incremental value of that plan to them $(\$ 40)$ is greater than its additional cost $(\$ 30)$. For low risks, the opposite is true $(\$ 15<\$ 20)$.

We suppose that insurers charge the same premium for everyone enrolled in the plan. This may be because individuals are indistinguishable to the insurer, equal premiums are required by law, or employers adopt this policy to help spread risks. ${ }^{1}$ Starting at the efficient equilibrium, the premiums that would cover costs in this case are $\$ 40$ for the moderate plan and $\$ 100$ for the generous plan. If these premiums were offered, however, all of the high-risk people would switch to the low-risk plan: the additional cost to high-risks of the more generous plan $(\$ 60)$ is not worth the additional benefit $(\$ 40)$. Thus, everyone will wind up in the moderate plan. The reason is simple: a person who switches from the generous to moderate plan benefits by mixing in with lower-risk individuals, and since premiums reflect risk mixes, this distorts choices towards the moderate plan.

A More Complete Model. We now examine adverse selection in a more realistic framework. As before, the employer offers two health insurance plans, generous and moderate. The generous plan may offer a greater choice of providers, lower cost sharing, or less officious gatekeepers than the moderate plan. The generous policy might be a fee-for-service (FFS)

1 Even if insurance premiums do vary across insureds, they may not fully reflect the cost differences that individuals know they are likely to experience. 
indemnity policy or a Preferred Provider Organization [PPO], whereas the moderate policy might be a Health Maintenance Organization [HMO]. For the moment, we take the characteristics of the two policies as fixed and focus on the employer's most important decision: what portion of the premium should he pay, and what portion should be charged to the employee?

Some discussion about this choice is relevant. Three decades ago, many employers offered just one health plan. Those who offered more than one plan frequently charged employees the same amount for each, subsidizing whatever difference there was between what employees paid and the premiums the plans charged the employer. The dollar amounts were not great, and the subsidy was tax advantaged, being deductible to the employer but not taxed to the employee.

Since then, health care costs have escalated and marginal personal tax rates have declined, making subsidies to health insurance less attractive. Employers have responded by reducing subsidies to health insurance. They have also sought to set employee charges for the different plans that would make their employees face appropriate incentives when choosing among the plans, which can now differ substantially in cost. A common practice is to offer the same dollar subsidy whichever plan was chosen, the so called "equal contribution" rule. Other employers subsidize a fixed percentage of each plan's costs. The question that we ask is how these two pricing strategies will affect outcomes. For expositional ease, we label as "premium" the per employee amount that plans charge for enrollment, "contribution" what the employer pays toward the premium, and "charge" the amount that the employer requires an employee to pay to enroll in a plan.

We assume employees know their expected sickness, $s$, which we normalize as expected 
spending in the generous plan. Sicker people will value the more generous policy over their healthier brethren since they will take greater advantage of its additional generosity. This differential value is represented as $\mathrm{V}(\mathrm{s})$, where $\mathrm{V}$ increases with $\mathrm{s}$.

Suppose that the employee charge to enroll in the more generous plan is D, for differential. All individuals who have $V(s)>D$ will enroll in the more generous plan; those who have $\mathrm{V}(\mathrm{s})<\mathrm{D}$ will choose the moderate plan. We denote enrollment in the moderate plan as a function $\mathrm{s}^{*}(\mathrm{D})$. As D increases, so does $\mathrm{s}^{*}$.

We now need to consider plan premiums and the employer's pricing decision. In general, we would expect the moderate plan to cost less than the generous plan for anyone. Moreover, the sicker the individual, the greater will be the differential in resource costs between the plans. We denote the cost for a person enrolled in the moderate plan as $\alpha$, where $\alpha<1$. Miller and Luft (1995), for example, estimate in comparing HMOs with fee-for-service plans that $\alpha=.9$.

Denote the mean level of $s$ for $s>s^{*}$ as $s_{G}$, with $s_{M}$ the mean for $s<s^{*}$, where the subscripts denote generous and moderate. These means are the spending per person enrolled respectively in the generous and moderate plans. If plans offer policies with no administrative load, then $P_{G}=s_{G}$ and $P_{M}=\alpha s_{M}$. The premium difference between the plans will be

$$
P_{G}-P_{M}=s_{G}-\alpha s_{M}=(1-\alpha) s_{M}+\left(s_{G}-s_{M}\right)
$$

The premium difference depends on two factors. The first is the resource cost savings in the less generous plan, $(1-\alpha) s_{M}$. The second factor is adverse selection; sicker people are more likely to be enrolled in the more generous plan $\left(\mathrm{s}_{\mathrm{G}}-\mathrm{s}_{\mathrm{M}}\right)$. 
Not all of the difference in plan premiums need be translated into differences in employee costs. Employers may make employees pay none, some, or all of the additional cost of the more generous policy. We consider two cases: In the equal contribution case, the employer pays a fixed dollar subsidy independent of plan, and the employee pays the difference between the subsidy and the premium for his plan. In the proportional subsidy case, the employer pays a fixed proportion of the premium cost of whatever plan the employee chooses, and the employee pays the rest. Holding plan design fixed, the interplay between the employer's pricing rules and the distribution of sickness in the population will determine the severity of adverse selection.

Figure 2 shows a possible situation with the equal contribution approach. Sickness, $s$, is assumed to be distributed uniformly from 0 to 1 . The $V(s)$ curve is upward sloping, reflecting the increased value of the more generous plan as $\mathrm{s}$ increases. The curve labeled "Actual difference" shows the difference in costs of medical care for a person of sickness $s$ between the two plans. Efficiency is achieved where the cost for the individual equals the gain in value he receives from the plan, as shown at point A. Efficiency requires that everyone to the right of $\mathrm{s}_{\mathrm{A}}$ be in the generous plan, and everyone to the left in the moderate plan.

However, the differential charges paid by employees will reflect not their own incremental costs, but rather the difference in average costs between the two plans for people who have currently chosen them. The curve labeled "Employee charge (equal contribution)" reflects the difference in what employees would pay as a function of $\mathrm{s}^{*}$, assuming $\mathrm{s}^{*}$ were the dividing line for plan choice. That is, those with sickness above $\mathrm{s}^{*}$ choose the generous plan and those with sickness below $\mathrm{s}^{*}$ choose the moderate plan (we assume that $\alpha=.9$ ). Given equal contributions by the employer, equilibrium in the market is achieved where the charged 
difference equals $V(s)$, at point $E_{C}$.

The actual equilibrium is far from efficient -- many fewer people will be in the generous plan than ought to be in that plan. Indeed, for some combinations of $\mathrm{V}(\mathrm{s}), \alpha$, and the distribution of s, the generous plan empties completely. This is termed an "adverse selection death spiral". Initially, the fact that the equal contribution rule is inefficient may be surprising for economists, who believe that subsidies should be constant across alternatives. For example, if employers were giving employees choices among computers, an equal contribution rule -"Here's a fixed subsidy, pick the computer you want." -- would be optimal. However, the cost of a health plan depends on who chooses it. The same is not true for computers; hence, the equal contribution rule is efficient because the individual pays the difference in cost if he chooses a better computer. The equal contribution approach to health plans fails because it does not charge individuals the difference in costs that they impose when changing plans. Rather, it charges individuals the difference in average costs for people who choose the different plans, and populations can vary dramatically from plan to plan due to adverse selection.

For health insurance plans, the optimal second-best single charge is roughly the average difference for all individuals who are close to indifference between the two plans. The cost difference for the marginal individual, not the average individual, is the appropriate basis for pricing those who currently have to decide among plans.

A common alternative approach for employer subsidies is to pay a constant percentage of the premium, implying that some plans get a greater dollar subsidy than others. The diagram shows a proportional plan with an 80 percent subsidy. The equilibrium is at $\mathrm{E}_{80}$. Note that far fewer individuals choose the moderate plans with the proportional subsidy than with the equal 
contribution rule. Within a fixed employer budget, the proportional subsidy has the employer pay more and the employee less for the generous plan. Hence, it gets chosen more often. In effect, proportional subsidies provide an indirect approach to "risk adjusting" plan payments, a topic we return to below.

At the outset, we mentioned three difficulties flowing from adverse selection. We now briefly describe the other two.

Loss of Risk Spreading. The second loss from adverse selection is that there is less risk spreading than is optimal. In the adverse selection equilibrium, sick people wind up paying substantially more for health insurance than healthy people because they choose the more expensive plan and because they are mixed in with other sick people. If we asked people in advance, they would want to insure against the risk that they will be high cost and thus would prefer the generous and more expensive policy. And they would want to insure more still if there were additional costs due to adverse selection. Yet there is no way to purchase insurance against the condition of wanting high coverage; the absence of a market generates an efficiency loss.

Consider three polar pricing approaches for two plans: (1) charging the employee the same amount for each plan; (2) charging employees the actual difference in their expected costs across plans; and (3) making equal contributions across plans so that employees are charged the full difference in plan premiums. The first approach would spread risks fully, but it would suffer moral hazard - all insureds would pick the generous plan because it is available at no extra charge. The second approach would eliminate adverse selection, but there would still be a riskspreading loss -- the sick would spend more than the healthy for medical insurance. The third 
approach would have more risk-spreading losses than the second: cost differences due to adverse selection would be added on to actual cost differences.

If insureds could contract before knowing their condition, they would prefer a price difference lying between the first and second approaches, where the increased risk spreading loss from increased greater differences is just balanced by the reduction in losses from moral hazard because the generous policy is insufficiently priced. The polices would be priced closer together than their actuarially fair amounts, and much closer together than the equal contribution rule would produce.

Plan Manipulation. The third inefficiency from adverse selection derives from manipulation of plan offerings by insurers. The premiums that insurers are paid may not fully reflect their population mix, say because premiums are set in advance, or because employers do not fully assess the mix of enrollees before bargaining with a plan over the premium. In such circumstances, premiums will stay the same even if healthier people enter a plan or sick people leave it.

In such circumstances, insurers will have incentives to attract healthy insureds and repel sick insureds, a process called risk selection. Merely denying enrollment to sick or high-cost people is usually prohibited by employers; more subtle methods are needed. Utilization management -- onerous processes for referrals or follow-up visits, or high copayments -- are ways to disproportionately discourage high-intensity users. Discounts for memberships in health clubs might attract the right people, an outstanding oncology program the wrong ones.

Plans will also be sensitive about what they are known to offer. The Massachusetts 
Group Insurance Commission (discussed below) conducted an informal study in 1994 of the mental health services of $10 \mathrm{HMOs}$ they offered their enrollees. Each claimed to enrollees to offer the minimum mental health coverage mandated by the state. In fact, however, 8 plans actually offered more generous benefits for critical cases. They did not advertize this fact because they wanted to avoid being selected against. ${ }^{2}$

Plan manipulation may impose significant losses, denying both sick and healthy coverage they would most like. Even though people would pay a lot for the best cancer care, no plan may provide it.

\section{A Tale of Two Entities}

To examine the empirical importance of adverse selection, we focus on the experience of two entities that allow individual choice over health insurance plans: Harvard University and the Group Insurance Commission (GIC) of Massachusetts (the purchasing group for state and local employees in Massachusetts). The two groups are similar in many respects: both offered a costly, generous plan and several HMOs (many of which serve both Harvard and the GIC); both have a long-term commitment to providing high-quality insurance; and both have been attempting to save money by reducing their health insurance costs over time.

But as we shall see, the recent experiences of these two entities is remarkably different, primarily because of how they have chosen to subsidize different health plans.

${ }^{2}$ Charles Slavin, personal communication, May 21, 1997. 


\section{Harvard University}

Harvard University offers health insurance to about 10,000 full- and part-time employees. ${ }^{3}$ Beginning in 1992, Harvard offered two types of health plans: a generous PPO run by Blue Cross/Blue Shield of Massachusetts, and several HMOs. Figure 3 shows the real (\$1996) premiums for a family policy in the PPO and the average HMO. (Throughout the paper, all dollar amounts are in real (1996) dollars and premiums and charges are for a family policy. ${ }^{4}$ ) In its first year 1992, the PPO cost about $\$ 500$ more than the HMOs, because in the absence of information about the enrollment mix, the initial price was set very high. Over the next two years, the PPO and HMO premiums converged to within a hundred dollars of each other.

Because the premiums for the different plans were so similar, the additional cost to the employee of the PPO was generally low. As Figure 4 shows, between 1992 and 1994 employees paid an average of about $\$ 400$ to $\$ 500$ to enroll in the PPO instead of an HMO. ${ }^{5}$ The Figure also shows that enrollment in the PPO was stable, at about 20 percent of Harvard employees.

In the mid-1990s, the University faced a budget deficit. The rising cost of health benefits was identified as an important culprit in the deficit. Harvard undertook a two-pronged response

${ }^{3}$ See Cutler and Reber (1996) for more detail on the Harvard experience.

4 Some analyses use a weighted average of family and individual premiums. We choose instead to rely on a particular commodity found in the market.

${ }^{5}$ We ignore issues of the tax status of these payments. Employee charges at Harvard are made on a pre-tax basis, so the after-tax contribution, in terms of consumption given up to enroll in the PPO, is smaller. 
to the health cost run-up. First, it implemented an equal contribution rule for each of the plans. This arrangement began with about half of the employees in 1995; the other half joined in $1996 .^{6}$ The additional cost of more expensive plans is now paid by the employee. Second, Harvard engaged in strenuous negotiations with its health insurers. Harvard stressed that its new equalcontribution policy would produce large enrollment swings towards plans with lower rates and pressed its insurers to reduce their premiums.

Premiums for the HMOs fell substantially in 1995 in response to these measures. In that year, HMO premiums fell by close to $\$ 1,000$ in real terms, as shown in Figure 3, while PPO premiums remained constant. These rate developments translated this into a notable increase in the employee charges to enroll in the PPO, as shown in Figure 4. In 1995, the cost of the PPO rose about $\$ 500$, to roughly $\$ 1,000$.

As expected, the initial response to this price increase was a reduction in PPO enrollment. As Figure 4 shows, PPO enrollment in 1995 fell from 20 percent to 15 percent, a significant response given that only half of the employees were affected by the change that year.

The employees who disenrolled from the PPO were healthier and younger than those who stayed (a mean age of 46 versus 51 years). As a result of the departure of the healthy, the PPO lost money in 1995, and had to raise premiums in 1996.

The rise in premiums in 1996 , combined with the change in policy for the remainder of the Harvard employees, resulted in a substantial increase in employee charges for the remaining PPO enrollees. As Figure 4 shows, the required contribution for the PPO, which was about $\$ 500$

\footnotetext{
${ }^{6}$ Union contracts prohibited an immediate change for all unionized employees.
} 
in 1994, rose to more than $\$ 2,000$ in 1996 . Not surprisingly, enrollment in the PPO plummeted, to about 9 percent of total employees. Those who left the plan were again younger than those who remained; the average age difference was 5 years. Analysis by Blue Cross/Blue Shield showed that those who left the policy that year were 20 percent healthier than the average employee in the year before they left. As a result, the PPO lost substantial money once again. By the beginning of the 1997 rate negotiation period, it was clear that the PPO premium and charges would have to increase dramatically for the plan to break even. This was untenable both to the University and Blue Cross/Blue Shield, and the PPO was disbanded. Harvard's health insurance system lost its heavily populated PPO within 3 years of moving to an equalcontribution arrangement. The adverse selection "death spiral" twisted swiftly.

\section{The Group Insurance Commission (GIC)}

The GIC provides insurance to roughly 133,000 employees and 245,000 total lives, making it one of the largest insurance purchasers in New England and many times larger than Harvard. As the 1990s began, the GIC, like Harvard, offered a traditional, more generous and costly indemnity policy, and a passel of HMOs.

Figure 5 shows premiums charged to the GIC by the insurance plans. The annual premium for the indemnity policy was roughly $\$ 2,500$ higher than the HMOs' premiums. The GIC rule was that employees paid 10 percent of the cost for the policy they enrolled in and the state paid the remaining 90 percent; in 1995 the employee share was increased to 15 percent. $^{7}$

${ }^{7}$ There was a small add-on for the indemnity policy for a catastrophic rider that most employees took. Thus, the employee charge for the indemnity plan was about 15 percent through 
These employee shares are set by the legislature. (It is believed that most legislators are enrolled in the generous indemnity policy.) Such proportional subsidies heavily subsidize the high-cost policies. As Figure 6 shows, the indemnity policy cost employees only about $\$ 600$ more than an HMO. Enrollment in the indemnity policy was relatively constant from 1990 to 1994 at about 30 percent (see Figure 7).

In 1994, the GIC consolidated a number of Blue Cross/Blue Shield HMOs into a PPO, also offered by Blue Cross/Blue Shield. The idea behind the plan change was partly to eliminate some marginally performing HMOs and partly to encourage relatively healthy HMO enrollees to move into the experience-rated PPO and indemnity plan. This effort largely succeeded; the PPO drew a number of people from the HMOs, and enrollment in the indemnity policy actually increased. The risk mix in the PPO was sufficiently favorable that in 1995 the PPO premium fell to roughly the level of the HMOs.

The GIC thus appears to offer a quite stable plan menu. But over the course of the 1990s, adverse selection has been a serious issue. The indemnity policy has slowly been losing population, dropping to 27 percent of all enrollees by 1997 .

Real premiums for the HMOs have been flat or falling in recent years, while the costs of the indemnity policy have continued to rise. Real HMO premiums declined $\$ 400$ between 1994 and 1997; real premiums in the indemnity policy rose over $\$ 500$ (see Figure 5). The reduction in HMO premium growth is not unique to the GIC: HMO premiums have not increased substantially in the Boston area for the past few years (Cutler and Reber, 1996).

1994 and about 20 percent after 1995. 
To examine the importance of adverse selection in the GIC, and to consider potential solutions to the adverse selection problem, we obtained detailed data on all the health insurance claims of GIC enrollees over the 30-month period encompassing Fiscal Years 1994, 1995, and the first half of Fiscal Year 1996. With 245,000 people, the number of claims is quite large: nearly 65,000 hospitals admissions, and almost 15 million outpatient records.

The distribution of medical spending in the GIC pool is heavily skewed, as it is nationally. The upper 10 percent of people in a year account for two-thirds of the total dollars spent; indeed, the top 1 percent of spenders account for nearly 30 percent of medical dollars (see Table 1). This is very close to the distribution of spending in national samples (Berk and Monheit, 1992).

Table 2 shows some evidence on adverse selection. The Table shows the share of enrollees in each type of plan in 1994 by age. ${ }^{8}$ The HMOs had 27 percent of their enrollees above age 45 and the PPO had 25 percent, whereas the indemnity plan had 50 percent above 45 . Since medical spending is substantially greater for the old than for the young, the implications of these mix differentials on costs are significant.

The last two rows provide summary measures for demographic selection. Using data from the 1987 National Medical Expenditure Survey, we computed average spending by age and sex. We then form a weighted average of "projected spending" in each plan, using the plan's

a The GIC reimburses plans the same amount for each enrollee regardless of age, and requires plans to accept anyone who wants to enroll in the plan. Hence, differential selection by age is an important form of adverse selection.

9 We divided the population into 9 age groups: $<1,1-4,5-14,15-24,25-34,35-44,45$ $54,55-64$, and $65+$. 
demographic enrollment shares as weights. The average HMO enrollee would be predicted to spend $\$ 1,264$; in contrast, predicted spending in the indemnity policy is $\$ 1,623$, or 28 percent higher. Recall that the premium in the indemnity policy is about 40 percent higher than the premium in the HMOs; the demographic mix of enrollees explains $28 / 40$, or over two-thirds of that difference.

Selection by age tells only a part of the story. For example, people of a given age who do not expect to need substantial medical care are likely to opt out of the indemnity plan, whereas those who do will opt in. To examine the importance of selection by health status, we focus on two important conditions for the under-65 population: pregnancy, and heart attacks. Both are expensive; births cost several thousand dollars on average and heart attack costs average nearly $\$ 25,000$.

Table 3 shows age- and sex-adjusted incidence rates for pregnancy and heart attacks. In each case, we find the rates in each plan by five-year age group (15-44 year-old women for pregnancy, 45-64 year-old men and women for heart attacks) and then form a weighted average for each type of plan. ${ }^{10}$ Both pregnancy and heart attack rates are higher in the indemnity plans than in the PPO, and both are higher in the PPO than in the HMOs. The differences are fairly large: after adjusting for age and sex, individuals in the indemnity plan have 30 percent more pregnancies and 90 percent more heart attacks than those in the HMOs.

We use claims information on individuals in the first two years of enrollment, 1994 and 1995 , to examine whether selection is increasing or falling over time. Overall, transitions across

\footnotetext{
${ }^{10}$ The weights are the share of the entire population in the GIC in that age and sex group.
} 
plans are relatively small. About 2 percent of people move from the indemnity plan to an HMO each year, and about 1 percent move in the reverse direction. The stickiness of plan choice from year to year is consistent with the evidence in Neipp and Zeckhauser (1985). Of course, the proportion of switchers might accelerate, as Harvard saw, if the indemnity plan were to lose its "excess" subsidy, so that the charge for the indemnity plan would jump substantially.

Table 4 shows information on the medical spending of individuals before and after they switch plans. We show the share of switchers by their quartile of the spending distribution before they switched (1994) and again after they switched (1995). If movement between plans were random, the percentage in each cell would be 25 percent. The first column of the Table shows that 43 percent of the people who moved from the indemnity plan to an HMO were in the lowest quartile of spenders in the indemnity plan in 1994. By contrast, the third and fourth quartiles of spending were under-represented among movers. In the subsequent year, people who moved to an HMO spent slightly less than normal, with 53 percent being below median.

Among movers from HMOs to the indemnity policy, the shares are about 25 percent in each cell. Thus, those leaving the HMOs are not those who are particularly expensive to treat in either an HMO or in an indemnity setting.

These patterns of movement tell an intriguing story of adverse selection, somewhat at variance with the traditional account within economics. In recent GIC experience at least, adverse selection occurs because low-risk people drop out of generous, high-cost plans; the selection in of high-risk people is not a significant factor. Since costs are skewed on the high end not the low, such dynamics affect the mix of costs less quickly.

The sense that the GIC plans are increasingly subject to adverse selection has been noted 
by the GIC commissioners. Over the past several years, the GIC has taken several steps to enhance the viability of the indemnity policy. First, it has made sure that budget savings apply to all plans roughly equally. For example, when the state needed to save money in 1992, cost sharing was increased for both HMOs and the indemnity plan, leaving the relative generosity of the plans roughly unchanged, even though some commissioners thought the indemnity plan should have been reduced more. ${ }^{11}$

Perhaps most important, however, the GIC has been actively involved in managing the indemnity plan to reduce its costs. In 1992, for example, the GIC completed a "carve out" of pharmacy benefits in the indemnity plan, subsequently extended to the PPO when it was established in 1994. Most pharmacy benefits are now provided on a mail-order basis, with a pharmacy PPO providing the rest. Bulk purchasing allows the GIC to save money on prescription drugs. Similarly, in 1994 the GIC "carved out" mental health and substance abuse benefits from the indemnity and PPO plans. When a person in either of these plans needs mental health services, these services are managed by a company that specializes in these conditions. As a result of the carve out, mental health expenditures have fallen from $\$ 25$ million to $\$ 10$ million per year (in nominal terms). The indemnity plan also manages outpatient benefits more tightly than a traditional indemnity policy does. High-cost outpatient users are now identified and their care is reviewed for appropriateness. And the indemnity plan has an exclusive contact with an

${ }^{11}$ Indeed, the GIC commissioned a relative value analysis of its 1996 plans (Group Insurance Commission, 1995). The difference between the most and least generous plans was just 1.3 percent. By contrast, the indemnity plan had a premium that was 90 percent above the cheapest plan and 40 percent above the second most expensive plan. The relative value calculation looks solely at plan benefits, and does not take into account how vigorously a plan is managed. Had it done so, it would have weakened the HMOs relative values. 
outpatient laboratory service for non-emergency services; again, bulk purchasing brings price discounts. Finally, using the leverage of substitution on laboratory services, the indemnity plan has bargained with its twenty-five highest cost hospitals in Massachusetts for lower rates.

As a final measure, the GIC is undertaking a thorough study of the health status of the individuals in its different plans, and their care utilization. From the results of this study, the GIC may undertake a "risk adjustment" scheme for its health insurance plans. Appropriate risk adjustment in pricing has the potential to substantially diminish any problems from adverse selection, as we discuss in the next section.

\section{Summary}

Our case studies suggest that adverse selection is a significant factor among employerbased health plans. In both the entities we examine, adverse selection became an important issue in recent years. And in both cases, the proximate reason for adverse selection is the same: healthy people selected out of the most generous plan as the cost of the less generous policies fell. At Harvard, the problem was not fully recognized until after the effects were known; at the GIC, the problem has been recognized, but no long-term solution has yet been implemented.

\section{Strategies to Deter Adverse Selection}

The most immediate issue raised by the experiences of Harvard and the GIC is: if an employer wants to deter adverse selection across insurance plans, how should it do so? How can we get individuals to select appropriate plans - plans they would choose if they faced the costs 
they would impose by switching from one plan to another?

One possibility would be to look at individuals' characteristics, and then assign them to appropriate plans, given geographic location, health status, and announced preferences. But such an approach would run contrary to the norms of our nation, and the movements of the health sector in recent years toward greater choice for consumers, and greater competition among health plans. We confine our analysis to decentralized systems, where individuals choose from a menu with varied plans and contribution rates.

Can we have such freedom of choice but avoid severe problems of adverse selection? Standardizing plans (e.g., requiring the same coverage in all plans) might help. That way, those with particular concerns, say mental health visits or diabetes care, will not migrate among plans to the one that is most generous for their needs. Indeed, the GIC staff recently proposed standardizing a variety of aspects of insurance plans, with adverse selection concerns in mind. ${ }^{12}$ Debate on the issue of standardization certainly focuses on the particulars of the benefits to be standardized. ${ }^{13}$

But there is another issue as well. Standardizing plan offerings may wind up impeding valuable competition on program design. For example, if the employer standardizes drug :

12 The proposal was, for all plans, to remove the $\$ 1$ million cap on lifetime expenditures; mandate a minimum of 80 percent coverage on durable medical equipment and appliances; mandate out-of-network benefits for mental health; set a $\$ 1,000$ maximum benefit for hearing aids; set standard visits and copayments for occupational, speech and physical therapy; allow annual pediatric exams up to age 18; implement a uniform $\$ 10$ copayment for formulary drugs and $\$ 15$ copaymant for brand name non-formulary drugs; and standardize vaccination and immunization coverage.

${ }^{13}$ One of the authors of this paper, for example, speculates that the copay charges for different types of drugs were likely set too close together. 
copayments (say for formulary generic, formulary brand name, and non-formulary brand name), HMOs will be inhibited in designing better plans on this dimension. And what is right for one plan may not be right for other plans, depending on the ability of plans to manage utilization or negotiate with providers. HMOs might not want limits on the number of well-baby care visits, for example, preferring to let people have all the visits their providers can spare, while fee-forservice plans may find such limits valuable. The more confident is the employer that he knows the optimal design of coverage and that this is optimal across plans, the more willing he should be to standardize plan choices. But standardization is not always called for.

Eveni f plans are standardized, however, they will still have disparate populations. If we wish to know the true cost of plans, the prices to charge employees if they are to make efficient choices, we will have to adjust for these disparities in plan enrollment. The employer can still offer freedom of choice, if he can price appropriately. Appropriate pricing means charging less than a plan costs if it has disproportionate numbers of high-risk people, and more than a plan costs if it disproportionately enrolls healthier people. In essence, we must adjust prices to account for the risk mix in each plan.

This section evaluates four potential mechanisms for risk adjustment.

\section{Premium Subsidies}

The crudest, albeit best known, method of risk adjustment is the one that Harvard employed prior to 1995 and that the GIC still employs: subsidize the premium of the most generous policy so that it is more affordable than risk differences alone would indicate.

While this solution has historically been the most common way to deter adverse 
selection, we do not believe it is the most appropriate solution. To begin, it pays no attention to the actual composition of populations within health plans; it simply assumes that if a plan is more expensive, that must be due to a worse mix of enrollees. While subsidizing premiums deters adverse selection, it also reduces the incentives for employees to choose their health insurance plans efficiently. Moreover, it eliminates any incentives for plans to operate efficiently or price competitively. Suppose, for example, that the most expensive plan raises its premium by $\$ 1$, in an effort to boost profits. If the employer is subsidizing the expensive policy by 90 percent, employees will see only a \$.10 increase in price. This substantially limits employees' incentives to seek out the most cost effective plans.

Some tentative evidence on the effect of subsidy rates on premiums is provided by the comparison of Harvard University and the GIC. As Table 5 shows, real HMO premiums fell more rapidly at Harvard after the equal contribution rule was implemented ( 9.7 percent annually between 1994 and 1996) than they did at the GIC (2.9 percent annually) in the same period. Indeed, Figure 3 shows a large decline in premiums at Harvard in 1995, the year that the equal contribution rule was implemented. This premium reduction was not matched at the GIC, despite the similarities of the policies offered. The more rapid decline in HMO premiums at Harvard did not merely offset more rapid premium growth prior to 1994 ; between 1990 and 1994, real premium growth at Harvard was also below the level at the GIC. This suggests that the equal contribution rule resulted in premium reductions for Harvard employees in HMOs.

We suspect that marginal subsidies to more expensive plans result in higher charges from the plans than would have otherwise prevailed. Since one goal for employers is to realize the lowest premiums possible, perpetuating a marginal subsidy to high-cost plans does not seem like 
the appropriate solution.

\section{Reinsurance}

A large share of medical expenditures are accounted for by the highest cost users. Thus, having mandatory reinsurance for high-cost people could be one way to risk adjust premiums. ${ }^{14}$ Suppose that all expenses over a certain amount (perhaps $\$ 25,000$ annually) were paid for out of a central account, which was funded by a uniform tax on all insurance premiums. Then, plans would pay for high-cost users in proportion to total revenues in their plan, not the specific enrollment of the high-cost group. If the high-cost group is primarily responsible for the high costs of the more generous plans, this could reduce the adverse selection problem. The compensating danger is hat once the expenses of high-cost users are pooled, the plans lose the incentive to monitor their utilization.

The reinsurance strategy bears parallels to the mental health/substance abuse carve out. In that case, all spending for a particular condition is removed from plan premiums; in the reinsurance case all spending above a certain amount is removed from plan premiums. The implicit rationale is that the individuals carved out, whether by condition or expense level, account for most of the adverse selection, measured on a dollar basis.

How much of the difference in costs would reinsurance overcome? If high spenders are the problem, then reinsurance may be the solution. Figure 8 shows the share of the difference between the indemnity policy and the HMOs at the GIC that is accounted for by particular parts of the spending distribution. For example, the last bar in the Figure shows that spending in

${ }^{14}$ See Cutler and Zeckhauser (1996) for a more general discussion of reinsurance. 
amounts above $\$ 100,000$ per person accounts for only 5 percent of the total spending difference between the two sets of plans. ${ }^{15}$ Indeed, spending above $\$ 25,000$ per year accounts for only 8 percent of the difference in spending between more generous and less generous plans. Contrary to what many would expect, the vast bulk of the difference between the plans is that small users in the indemnity policy average much higher annual claims than in the HMO. Spending in amounts below $\$ 5,000$ per person accounts for two-thirds of the overall differences in plan costs. This may be the result of more severe moral hazard in the indemnity policy, different prices paid for services, or less restrictive use of gatekeepers.

If risk mixes for patients who are not extremely expensive to treat differ substantially among plans, then reinsurance for high-cost users will not accomplish much in the way of reducing the consequences of adverse selection.

\section{Prospective and Retrospective Risk Adjustment}

The final two methods of risk adjustment are prospective and retrospective adjustment. Older people, women of child-bearing age, and people with certain conditions spend more on medical care than those in other groups or without those conditions. Thus, if we could measure the distribution of plan enrollees ex ante or ex post, we could adjust per capita payments to each plan to account for these differences. If the plans are compensated for the differences in risk of their insureds, then in a competitive market premiums will differ only by their pure efficiency

15 Note that this is not total spending of people using over $\$ 100,000$ of services in a year but rather the amount of that spending that is above $\$ 100,000$. Under a reinsurance system, this is the amount that would be reinsured. 
differences.

Using the notation of Section II, suppose we observed $s_{\mathrm{G}}$ and $\mathrm{s}_{\mathrm{M}}$, the average healthiness of enrollees in the more and less generous policies. Then, we could set employer payments across plans of $E_{G}=s_{G}$ and $E_{M}=s_{M}$. Since these payments would eliminate the bias in employee charges caused by adverse selection, the only difference in charges facing employees would be the efficiency savings in the moderate plan. This charge arrangement provides employees with appropriate incentives to choose the most efficient plan. ${ }^{16}$

Measuring risk differences ex ante is termed prospective risk adjustment; measuring risk differences ex post is termed retrospective risk adjustment. If these methods can be implemented effectively, they will yield the right prices, and individual choices will produce an efficient outcome. The major question is whether all the factors that influence costs can be observed. For example, not all people with high blood pressure will have a major cardiovascular incident. If among those with high blood pressure, the people who sense they are more likely to have a major incident select into the more generous policy, a risk adjustment strategy based only on the presence or absence of high blood pressure would be incomplete.

The incompleteness of risk adjustment is problematic because the distribution of medical spending is so skewed. If individuals know they will be in the extreme tail of the spending distribution due to factors we cannot observe, adverse selection can still be economically

16 This works well if health plan choice depends only on s, so that the cost savings for the marginal person, indifferent between the plans, will appropriately guide the market. But if personal preferences also play a role (for example if say some low s people particularly like the indemnity plan), the correct price would be different for each person and charging everyone the same price would not be efficient. 
important even if risk adjustment is good "on average". Our GIC data suggested that most of the difference in costs across plans was not in the tail of the distribution. The experience of other entities may differ, perhaps due to differing historical patterns of plan offerings.

Prospective or retrospective risk adjustment will be severely hindered if insurers can alter their coding practices in light of the risk adjustment system. For example, if employers pay a surcharge to plans that enroll people with high blood pressure, and insurers pay particular attention to note whether a person has that diagnosis, the risk adjustment system will depend on the ability and willingness of insurers to record this information accurately, as much as on the true incidence in the population. Indeed, this "upcoding" problem was particularly severe with the implementation of the DRG rating system for Medicare (Carter and Ginsberg, 1985).

Research on effective risk adjustment methods has been progressing rapidly (see Newhouse, Beeuwkes, and Chapman, 1997, for a review). Current methods of prospective risk adjustment can explain about 5 to 10 percent of the variance in individual medical spending. While this is not large, in designing a risk adjustment system we care about the share of expected medical spending that can be explained, not actual medical spending. Estimates of the difference between expected and actual medical spending suggest that expected spending differences are about 20 to 25 percent of actual spending differences, so that current risk adjustment systems achieve 20 percent $(5 / 25)$ to $50(10 / 20)$ percent of ideal effectiveness.

Whether this degree of success - with or without reinsurance — is enough to limit adverse selection, we do not know. To date, there have been few experiments of insurance choice in a system with risk adjustment that would allow us to provide an answer. 


\section{Conclusions}

Most Americans receive health insurance through plans that are administered by and subsidized by employers. Typically, charges to employees depend on the plan they choose -- the higher the premium to the employer, the higher the charge to employees. The result is that people who choose more generous insurance policies must pay to subsidize the sicker people who choose the more expensive policy. This arrangement invites adverse selection.

The experiences of Harvard University, which provides equal contributions across plans, and the Massachusetts Group Insurance Commission (GIC), which subsidizes 85 percent of premiums regardless of plan cost, show that adverse selection is a real world concern. Harvard's PPO crashed in a death spiral when it implemented an equal contribution rule. Adverse selection was so great that the most generous policy could not be offered at a reasonable price. The GIC has avoided such a situation, in part by not moving to an equal contribution rule and in part by undertaking steps to reduce the costs of the most generous plan. This has been challenging, however, and adverse selection remains a concern.

To get the right insureds to take the right plans, employees who are given a choice across plans should be charged the differential in cost that applies for them. The mixes of insureds in the actual plans should not affect charges to employees; only the cost savings for a particular individual should affect his decision. In such a system, employers will vary the premium across plans based on ex ante differences in demographics and observed health status across plans, and may make further corrections to payments based on ex post claims experience. Careful empirical assessment is essential to guide this process. For example, two of our most important findings 
about the GIC were surprises: spending above $\$ 25,000$ per year accounted for only 8 percent of the difference in costs between the indemnity and HMO policies, and the vast majority of adverse selection resulted from the movement of low-risk employees. Implementing a carefully designed and empirically informed risk-adjustment system is essential to make health insurance competition work well. 


\section{References}

Berk, Mark L., and Alan C. Monheit, "The Concentration of Medical Expenditures: An Update", Health Affairs, 1992, 11(4): 145-149.

Buchmueller, Thomas C., and Paul J. Feldstein, "Consumers' Sensitivity to Health Plan Premiums: Evidence from a Natural Experiment in California", Health Affairs, Spring 1996.

Carter, Grace, and Paul B. Ginsberg, "The Medicare Case Mix Index Increase: Medical Practice Changes, Aging, and DRG Creep, Rand R-3292, June 1985.

Cutler, David M., "Restructuring Medicare for the Future", in Robert Reischauer, ed., Setting National Priorities, Washington, D.C.: The Brookings Institution, 1996.

Cutler, David M., and Sarah Reber, "Paying for Health Insurance: The Tradeoff Between Competition and Adverse Selection", NBER Working Paper No. 5796, October 1996.

Cutler, David M., and Richard J. Zeckhauser, "Reinsurance for Catastrophes and Cataclysms", NBER Working Paper No. 5913, February 1997.

Feldman, Roger and Bryan Dowd, "The Effectiveness of Managed Competition: Results from a Natural Experiment," Institute for Health Services Research, University of Minnesota, April 6, 1993.

Group Insurance Commission, "Relative Value Analysis of GIC Plans," Boston, MA: Group Insurance Commission, October 23, 1995.

Hill, Stephen C., and Barbara Wolfe, "Testing the HMO Competitive Strategy: An Analysis of Success and Failure in Wisconsin," The Robert M. La Follette Institute of Public Affairs Working Paper Series, 1993.

Miller, Robert and Harold Luft, "Managed Care Plan Performance Since 1980", Journal of the American Medical Association, May 18, 1994, 1512-1519.

Newhouse, Joseph P., Melinda Beeuwkes, and John D. Chapman, "Risk Adjustment and Medicare", mimeo, Harvard University, February 1997.

Neipp, Joachim, and Richard Zeckhauser, "Persistence in the Choice of Health Plans", in R.M. Scheffler and L.F. Rossiter, eds., Advances in Health Economics and Health Services Research, Vol. 6, Greenwich, CT: JAI Press, 1985, 47-74.

Rothschild, Michael, and Joseph E. Stiglitz, "Equilibrium in Competitive Insurance Markets: An Essay on the Economics of Imperfect Information", Quarterly Journal of Economics, $1976,80: 629-649$. 
Royalty, Anne Beeson and Neil Soloman, "Health Plan Choice: Price Elasticities in a Managed Competition Setting," Stanford University, October 1995. 
Figure 1

Differential Selection: Plan, Employer, and Employee Actions

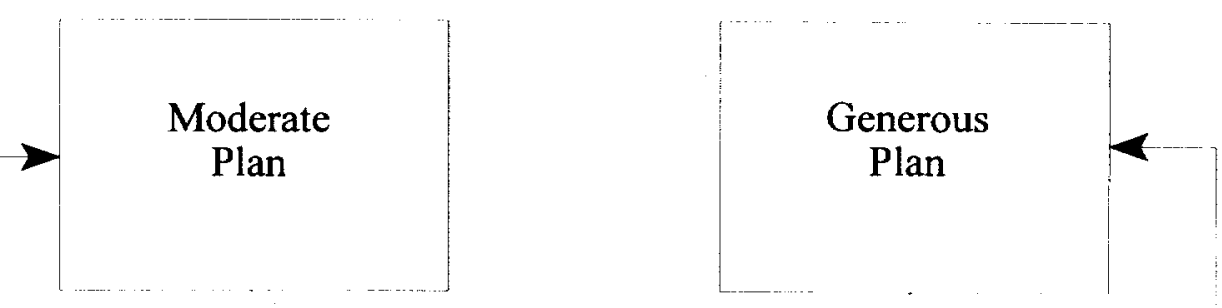

Set Premiums

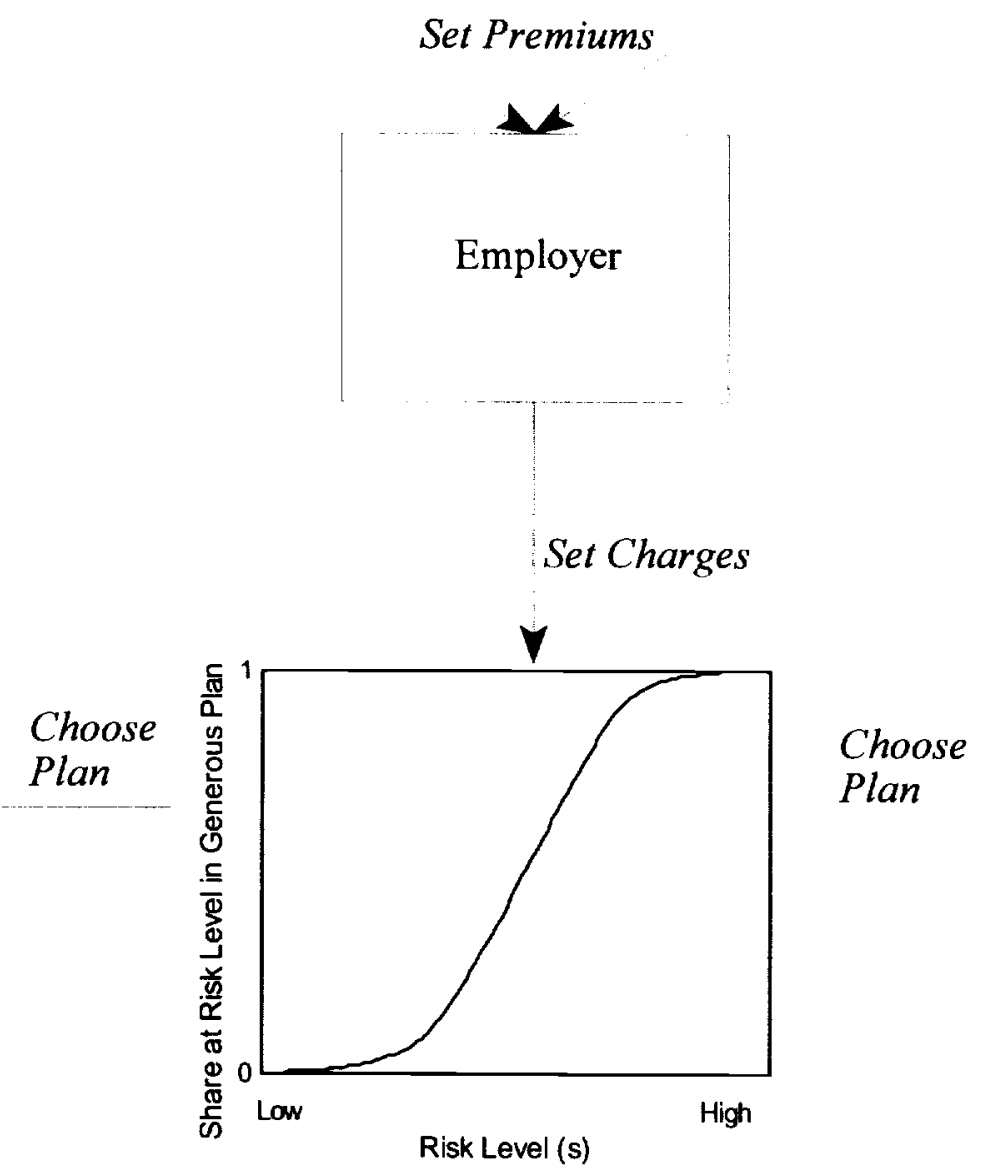


Figure 2: Plan Choice Equilibria

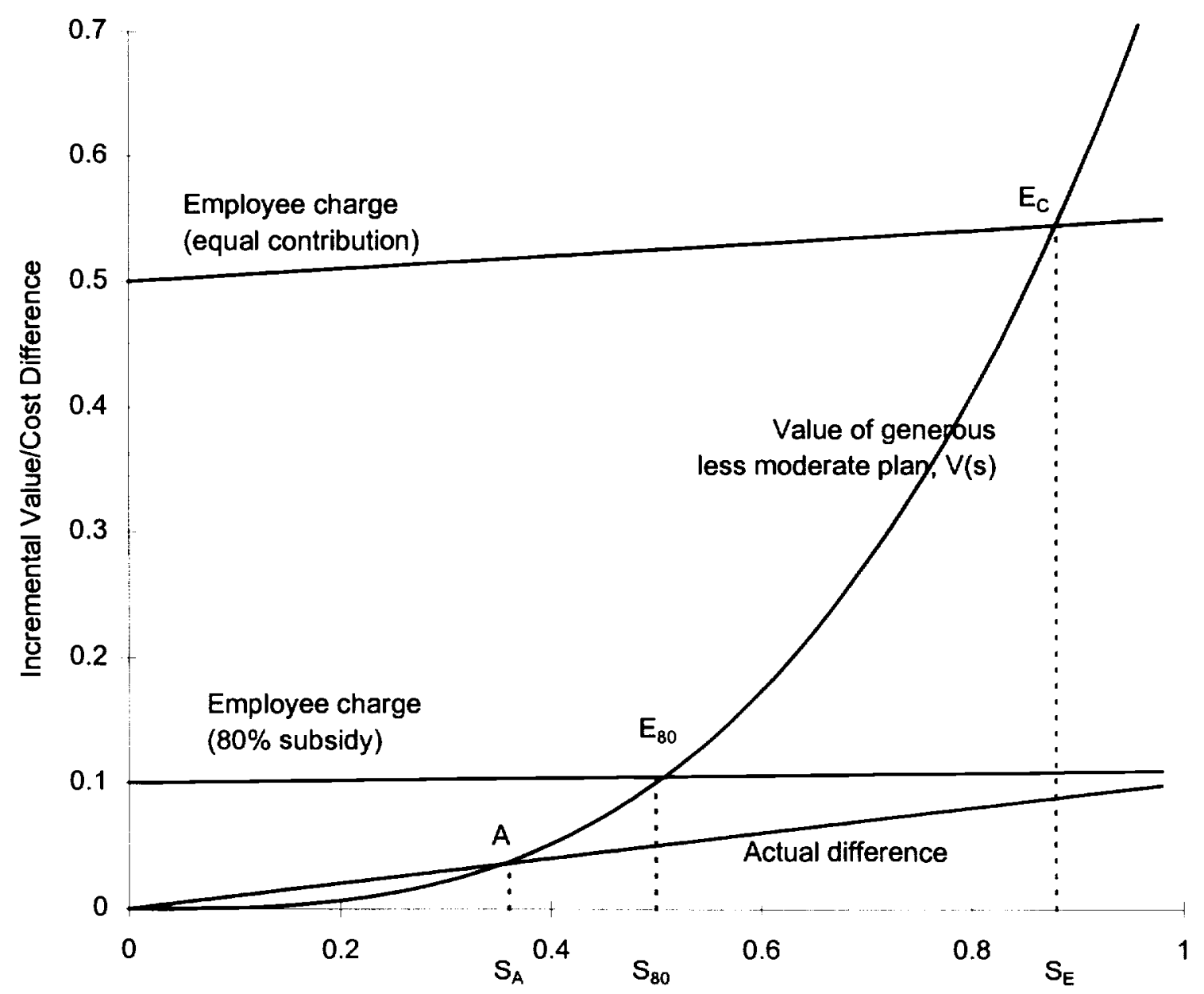

Share of People in Moderate Plan 
Figure 3: Real Family Premiums at Harvard

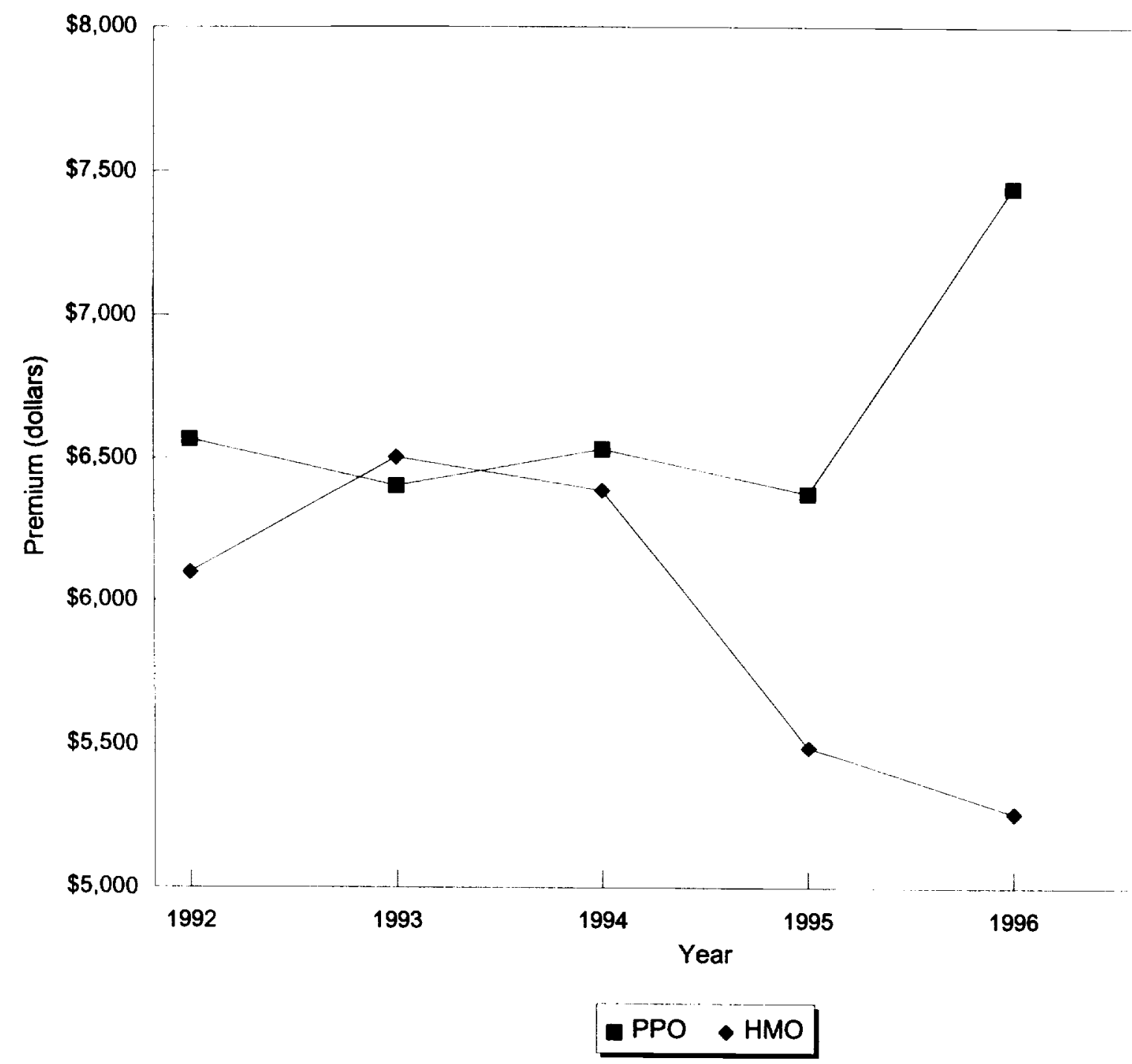

Note: Premiums are in 1996 dollars 


\section{Figure 4: Real Employee Charge for the PPO and Enrollment in the PPO at Harvard}

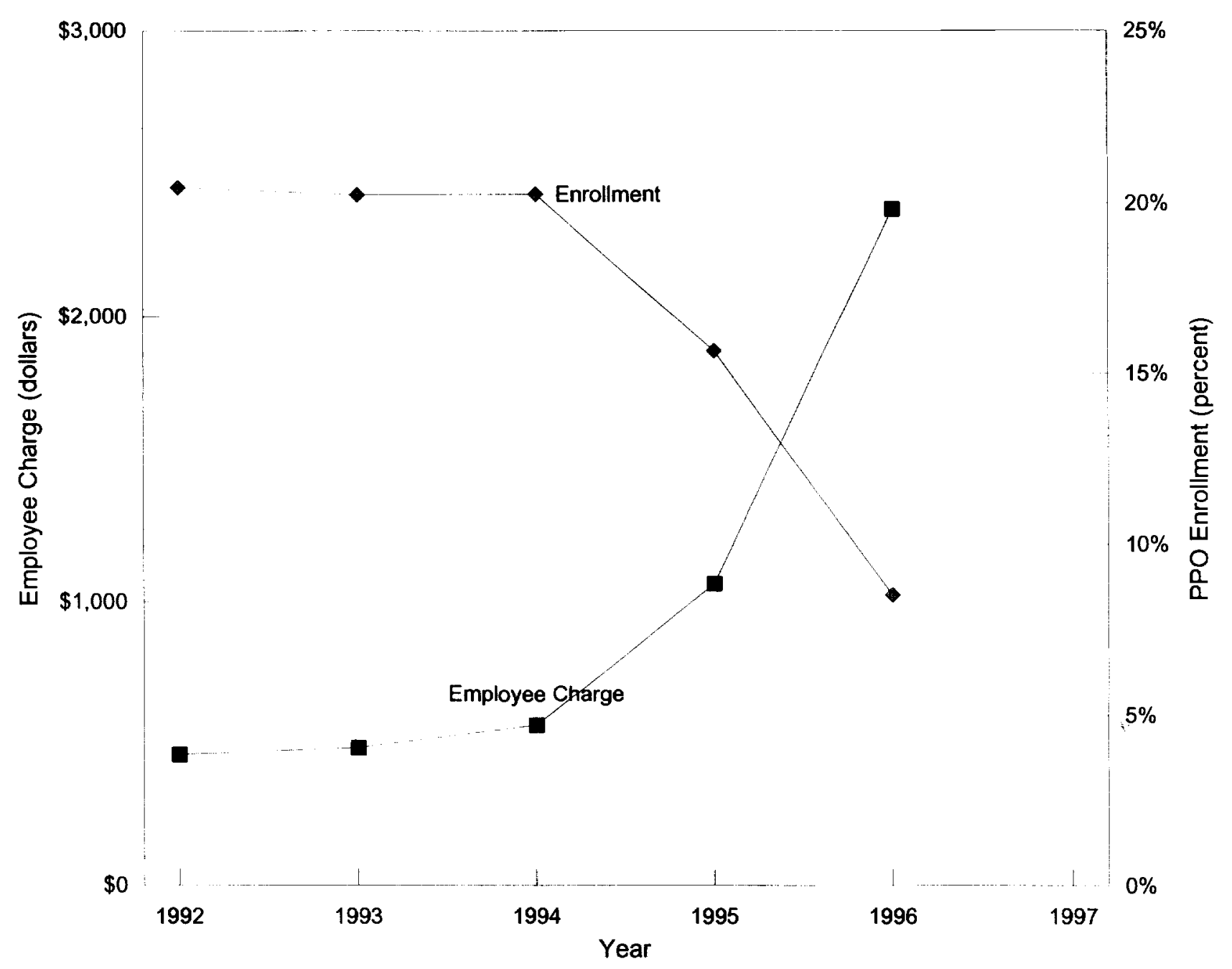

Note: Employee charge is in 1996 dollars and is for a family policy. 
Figure 5: Real Family Premiums in the GIC

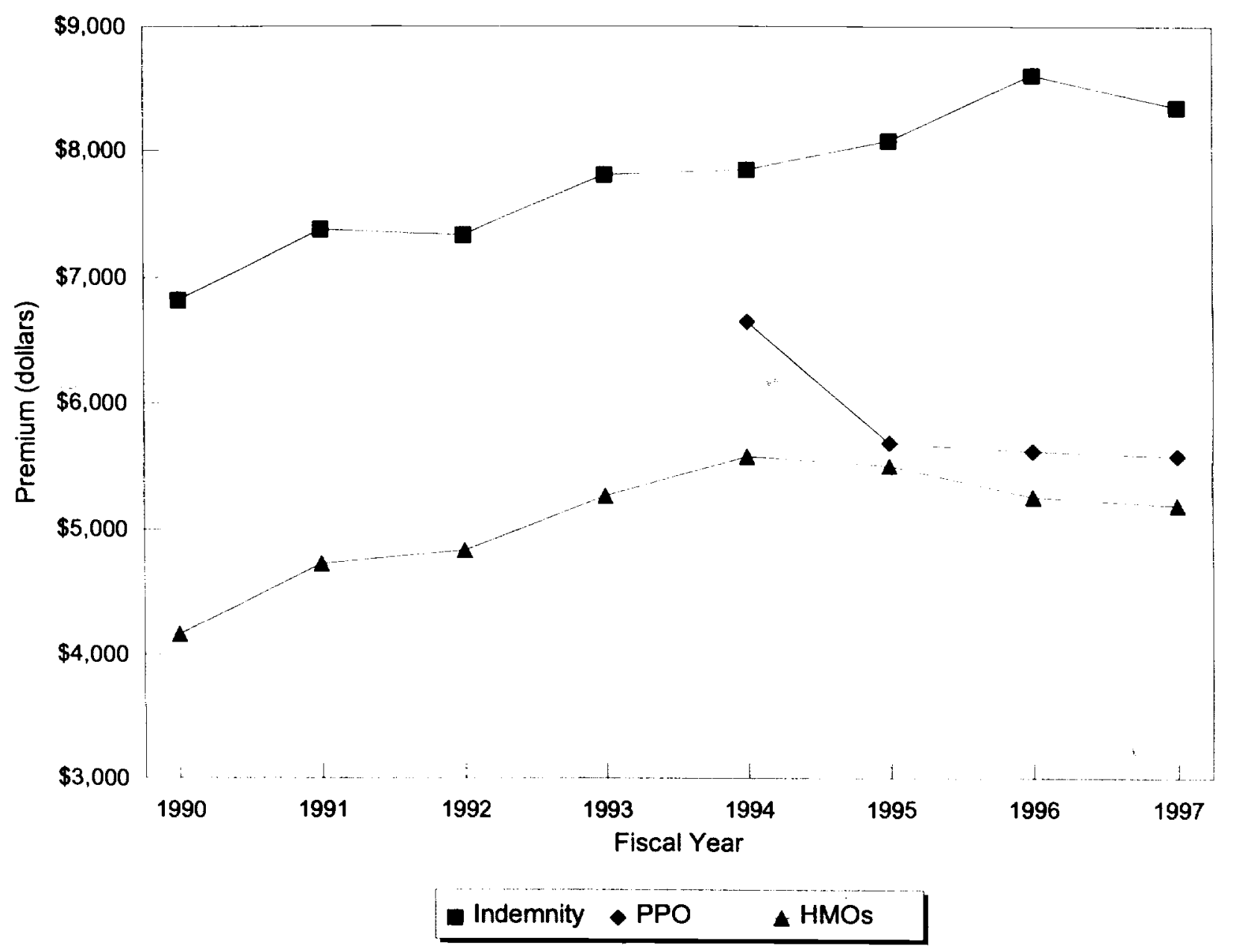

Note: Premiums are in 1996 dollars. 


\section{Figure 6: Real Employee Charge for Indemnity and PPO Policies at the GIC}

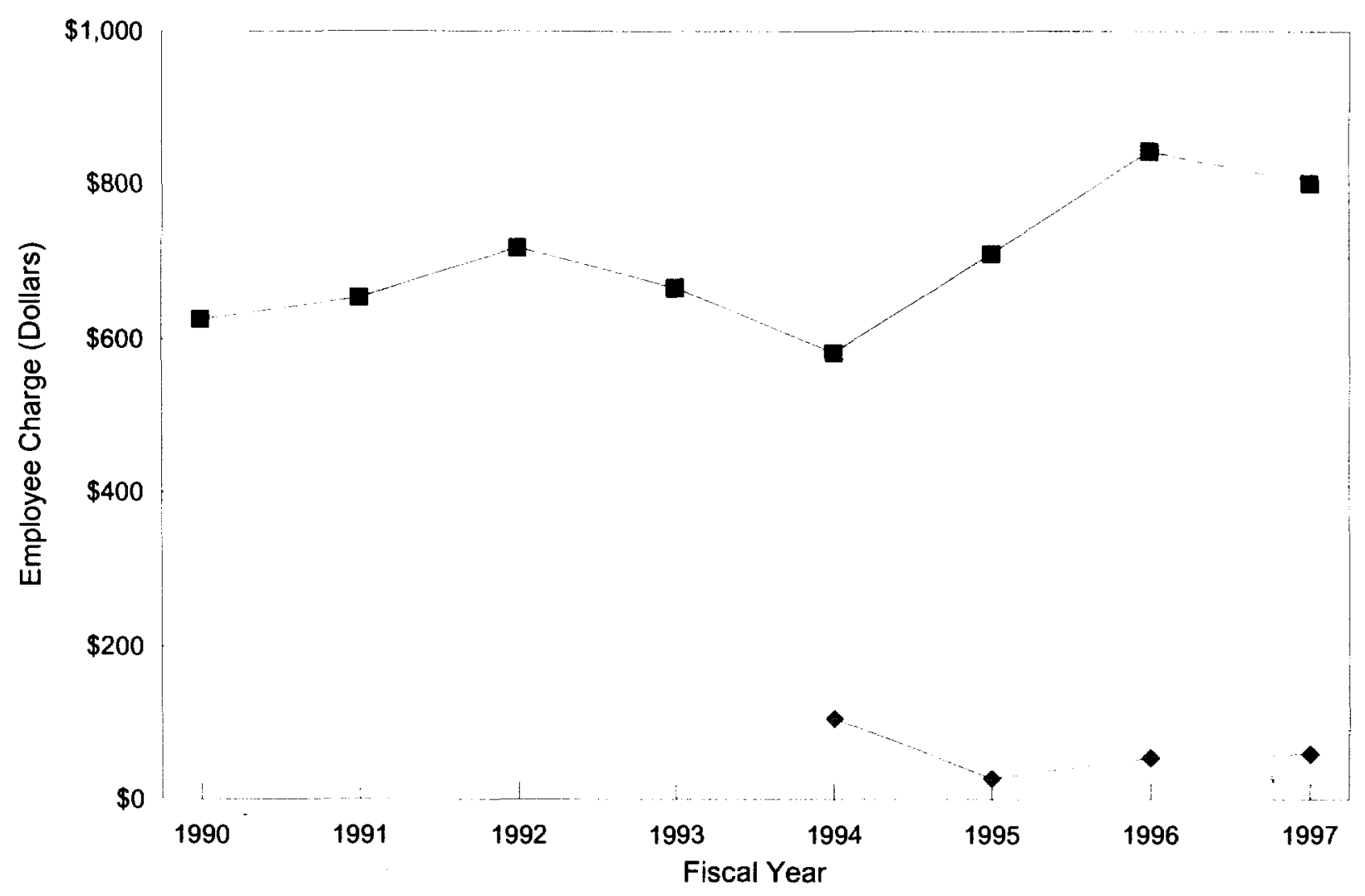

a Indemnity • PPO

Note: Employee charge is in 1996 dollars and is for a family policy. 


\section{Figure 7: Enrollment in Indemnity and PPO Policies At the GIC}

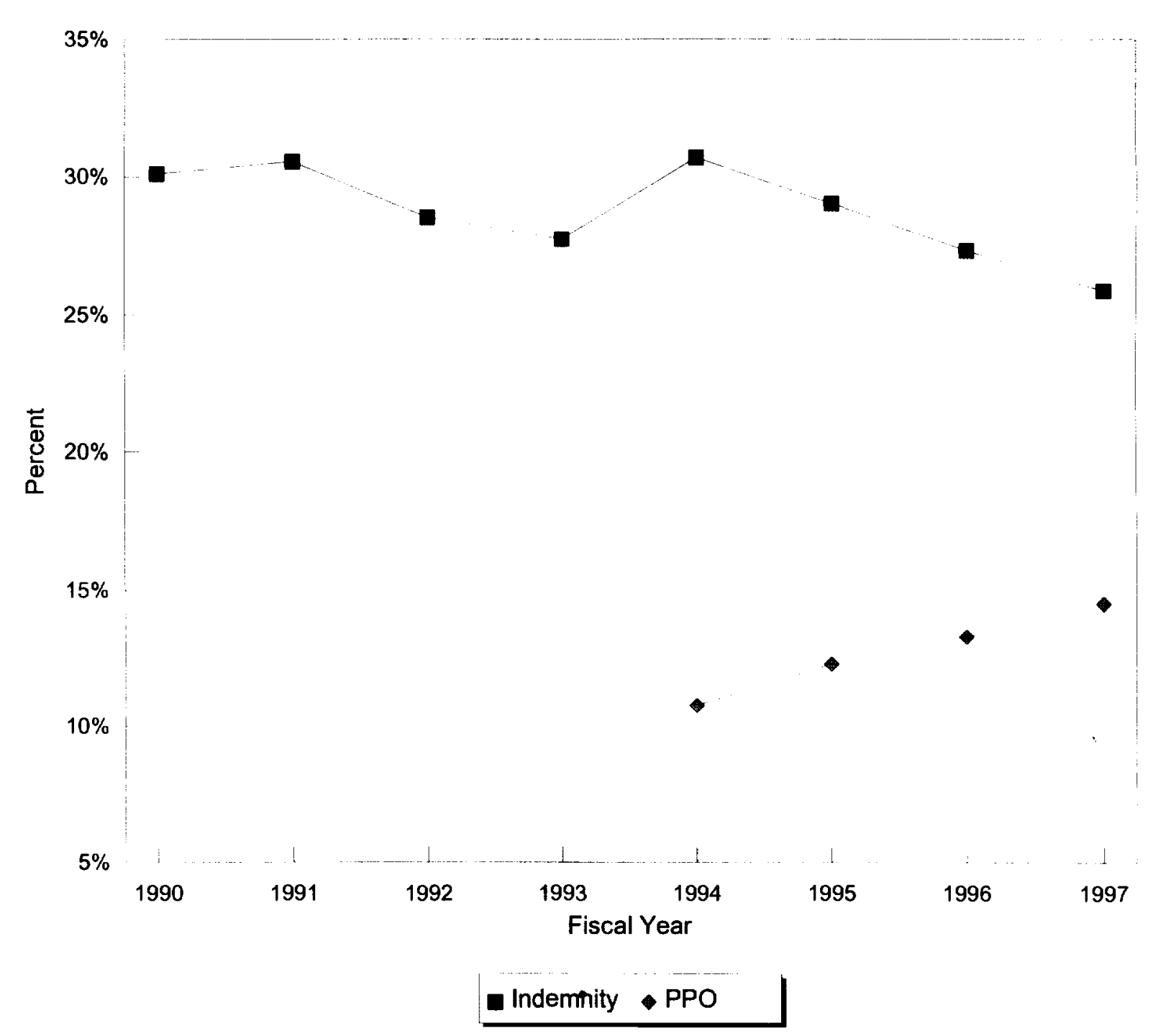


Figure 8: Share of Total Cost Difference by Spending Level, GIC

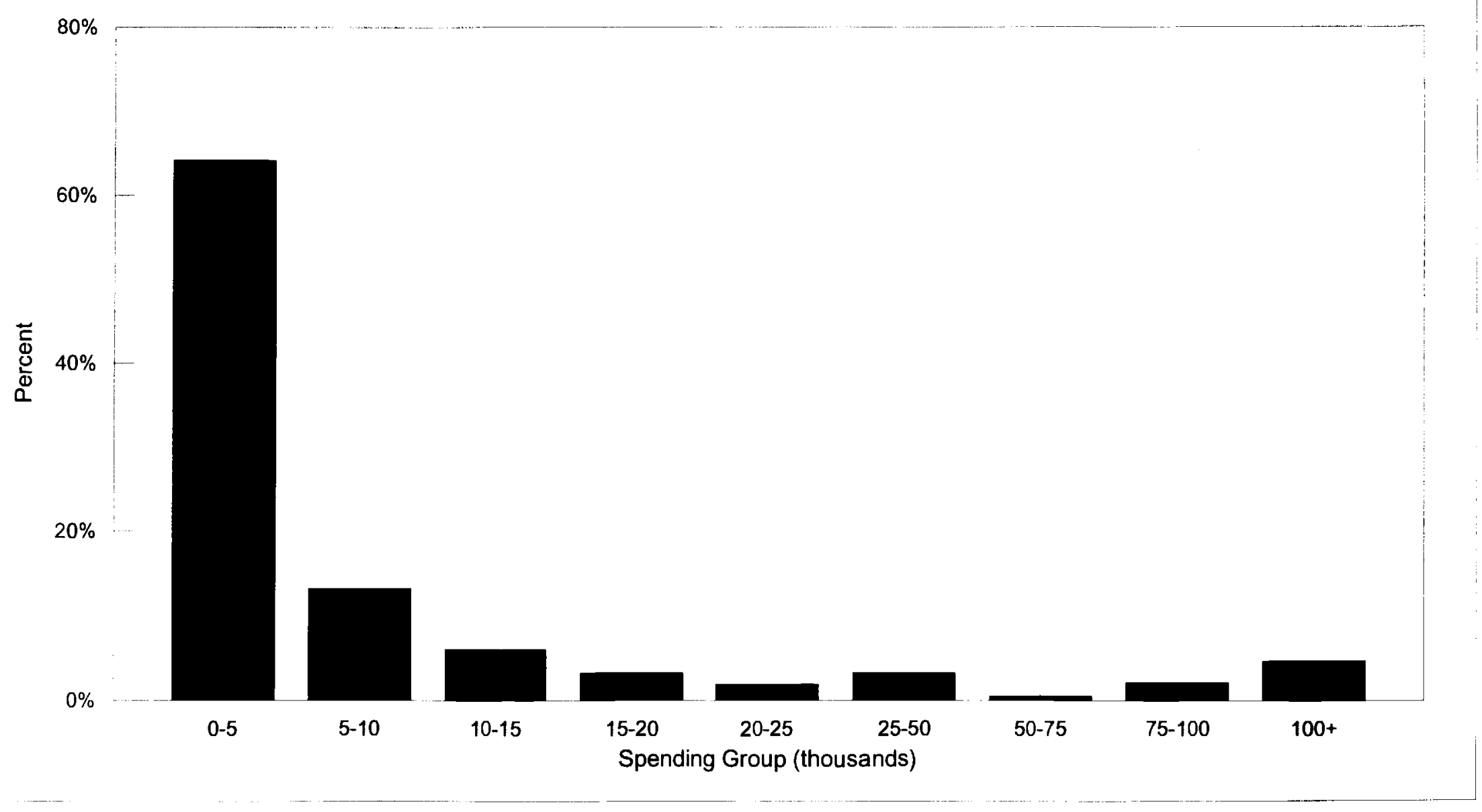


Table 1

Distribution of Spending in the GIC

\begin{tabular}{lcc}
\hline Percentile & Amount & $\begin{array}{c}\text { Cumulative } \\
\text { Share }\end{array}$ \\
\hline Mean & $\$ 1,944$ & --- \\
$10^{\text {th }}$ percentile & $\$ 60$ & $0.2 \%$ \\
$25^{\text {th }}$ percentile & 174 & 1.0 \\
$50^{\text {th }}$ percentile & 507 & 5.1 \\
$75^{\text {th }}$ percentile & 1,433 & 16.4 \\
$90^{\text {th }}$ percentile & 3,955 & 34.4 \\
$99^{\text {th }}$ percentile & 24,414 & 72.8 \\
\hline
\end{tabular}

Note: The data are for individuals in fiscal year 1994.

There are 180,837 observations. 
Table 2

Age Distribution Across Insurance Plans, GIC Data

\begin{tabular}{|c|c|c|c|}
\hline \multirow[b]{2}{*}{ Measure } & \multicolumn{3}{|c|}{ Plan } \\
\hline & Indemnity & PPO & HMOs \\
\hline Number of Enrollees & 76,185 & 22,434 & 128,709 \\
\hline \multicolumn{4}{|c|}{ Percent of Enrollees, by Age } \\
\hline$<1$ & $0 \%$ & $1 \%$ & $0 \%$ \\
\hline $1-19$ & 14 & 23 & 23 \\
\hline $20-44$ & 36 & 50 & 50 \\
\hline $45-64$ & 42 & 24 & 23 \\
\hline $65+$ & 8 & 1 & 4 \\
\hline Total & $100 \%$ & $100 \%$ & $100 \%$ \\
\hline Spending Index & $\$ 1,623$ & $\$ 1,194$ & $\$ 1,264$ \\
\hline [Ratio to $\mathrm{HMO}$ ] & {$[1.28]$} & {$[0.94]$} & {$[1.00]$} \\
\hline \multicolumn{4}{|c|}{$\begin{array}{l}\text { Note: Data are for fiscal year } 1994 \text {. The spending index is a } \\
\text { weighted average of the age- and sex-distribution of enrollees, } \\
\text { where the weights are average spending in } 1987 \text {. }\end{array}$} \\
\hline
\end{tabular}


Table 3

Age- and Sex-Adjusted Incidence of Plan Utilization, GIC Data

\begin{tabular}{lccc}
\hline & \multicolumn{3}{c}{ Percent with Condition, by Plan } \\
\cline { 2 - 4 } Condition & Indemnity & PPO & HMOs \\
\hline Pregnancy & $3.4 \%$ & $2.8 \%$ & $2.5 \%$ \\
Heart Attack & $0.51 \%$ & $0.34 \%$ & $0.27 \%$ \\
\hline
\end{tabular}

Note: Pregnancy rate is for 15-44 year-old women. Heart attack rate is for 45-64 year-olds. Both rates are standardized to the age distribution for the group as a whole using 5 year age and sex (for heart attack) groups. 
Table 4

Transition of Families by Plan and Position in Spending Distribution, GIC Data

\begin{tabular}{|c|c|c|c|c|}
\hline \multirow[b]{2}{*}{ Spending Quartile } & \multicolumn{2}{|c|}{$\begin{array}{c}\text { Indemnity } \rightarrow \text { HMO } \\
(1.8 \% \text { of Indemnity Enrollees })\end{array}$} & \multicolumn{2}{|c|}{$\begin{array}{c}\text { HMO } \rightarrow \text { Indemnity } \\
(0.9 \% \text { of HMO Enrollees })\end{array}$} \\
\hline & Indemnity & HMO & HMO & Indemnity \\
\hline $1^{\text {st }}$ (Lowest) & $43 \%$ & $29 \%$ & $26 \%$ & $26 \%$ \\
\hline $2^{\text {nd }}$ & 26 & 24 & 22 & 19 \\
\hline $3^{\text {rd }}$ & 15 & 27 & 25 & 27 \\
\hline $4^{\text {th }}$ (Highest) & 16 & 21 & 27 & 29 \\
\hline Total & $100 \%$ & $100 \%$ & $100 \%$ & $100 \%$ \\
\hline \multicolumn{5}{|l|}{ Average Spending } \\
\hline All & $\$ 6,833$ & $\$ 3,668$ & $\$ 3,173$ & $\$ 6,941$ \\
\hline Movers & 4,646 & 4,445 & 4,865 & 7,987 \\
\hline Ratio & $70 \%$ & $121 \%$ & $153 \%$ & $115 \%$ \\
\hline
\end{tabular}


Table 5

Change in Real HMO Premiums, Harvard and GIC

\begin{tabular}{lcc}
\hline & \multicolumn{2}{c}{ Annual Percent } \\
\cline { 2 - 3 } Period & Harvard & GIC \\
\hline $1990-94$ & $4.9 \%$ & $7.3 \%$ \\
$1994-96$ & $-9.7 \%$ & $-2.9 \%$ \\
\hline
\end{tabular}

Note: Each entry is the average annual percent change in real family premiums. Premiums are weighted across HMOs using contemporaneous enrollment rates. 